\title{
The Naples-Questionnaire of Work Distress (nQ-WD): Bullying at workplace, organizational dysfunctions and bio-psycho-social effects
}

\author{
Giovanni Nolfe $^{1}$, Maria Triassi ${ }^{2}$, Antonella Cappuccio ${ }^{2}$, Umberto Carbone ${ }^{2}$, Giuseppe Nolfe ${ }^{3}$ \\ ${ }^{1}$ Department of Mental Health, Work Psychopathology Medical Centre, Naples, Italy \\ ${ }^{2}$ Department of Preventive Medical Sciences, University of Naples Federico II, Naples, Italy \\ ${ }^{3}$ Institute of Cybernetics "E. Caianiello", National Research Council of Italy (CNR), Pozzuoli, Italy \\ Email: giovanni.nolfe@virgilio.it
}

Received 4 December 2011; revised 31 December 2011; accepted 13 January 2012

\begin{abstract}
The aim of this study is to elaborate a tool, the "Naples-Questionnaire of Work Distress” (nQ-WD), in order to evaluate the conditions of discomfort perceived in the working field. It tries to differentiate the dysfunctional phenomena more tied to the anomalies of the interpersonal relationships (bullying at workplace) from the phenomena more clearly related to organizational dysfunctions. The inventory measures the overall effects of these two areas on the subject and the spin-off in term of bio-psycho-social functioning. The questionnaire has been administered to a group of 178 workers who showed a work-related psychopathological disturbance and to a control group of 178 subjects without exposure to bullying at workplace or to organizational distress. The statistical analysis demonstrated degree of significant validity and reliability. The degree of internal coherence of the answers proposed is satisfactory. The ROC curves allow the determination of a threshold value which allows separating the workers subjected to mobbing and/or organizational stress from control-workers with an optimal reliability degree. The values of the area under the ROC curves show that the inventory has a high discriminating capacity.
\end{abstract}

Keywords: Bullying at Workplace; Organizational Stress; Work-Related Psychiatric Disturbances; Work Psychosocial Environment; Risk Assessment

\section{INTRODUCTION}

Over the last decades the topic concerning the workrelated distress and its relationship with poor mental health outcome has roused great clinician interest and many studies have underlined the psychopathological [1-6] and economic effects [7,8].
The distress features are linked to three main factors: 1) interpersonal conflicts; 2) organizational dysfunctions and 3) job insecurity. These factors are clearly characterized by a significant overlap and it's frequently difficult to distinguish and to separate these phenomena. For instance, the professional deskilling could be related to interpersonal conflicts as well as to organizational questions and produce subjective job insecurity.

In the area of the interpersonal conflicts the main phenomenon is constituted by the bullying at workplace, in which the psychological and emotional abuses are the central core [9]. Indeed, the concept of bullying at workplace (mobbing, harassment at the workplace, job injustice) is strongly linked to the psychiatric disturbances developing and this phenomenon has become of increaseing interest within the international literature both because of its negative psychological health outcome [1012] and of its health-care costs for poor mental health in the workplace [13,14].

As to the organizational distress, many studies of occupational medicine and psychology have underlined the relationship between the work psychosocial environment and the mental health $[2,4,15,16]$. The theoretical fields in which the organizational negative phenomena could be summarized are included into three main explicative models: the "job-demand control theory" [17], the "effortreward imbalance model" [18] and the "organizational injustice" [19].

Finally, the job insecurity is a well-known life-event stressor linked to the development of psychiatric disturbances [20-22], above all in the light of the more and more complex coping processes demanded by the new work environments linked to the economic globalization as well as to the productive and technological changes [23,24].

As already suggested, these areas are strongly overlapped and it's difficult to mark absolute categorical thresholds [25]. This observation is also founded on the hy- 
pothesis that the work environments in which bullying at workplace is highest also have poorer psychosocial work characteristics [26,27] and could explain the irresolution, underlined by some studies [28], about the operative definition of these phenomena and their different rates of prevalence [29].

Some methodologies have been proposed to evaluate the bullying at workplace: 1) fixed cut-off score to questionnaire [30];2) methodologies by means of which employees self-label into a specific bullying definition [31, 32]; 3) administration of check-list of items exploring the worker exposure to behaviors suggestive of bullying. The questionnaires most used to assess the subjective perception of bullying at workplace are the Leymann Inventory of Psychological Terror (LIPT), based on the Leymann studies from the 1970s [33], and the Negative Acts Questionnaire (NAQ) and its revised version [34,35], in which the assess (if the reported exposure to specific behaveiors could be or not to be interpreted as bullying) resides with evaluator.

The aim of our study was the achievement of the new measuring instrument Naples-Questionnaire of Work Distress (nQ-WD) and to validate it among Italian work sample. The need of a new assessing instrument, perceived within our clinical activity into the area of work psychopathology, was founded on the basis of three main points: 1) to differentiate the dysfunctional phenomena more tied to the anomalies of the interpersonal relationships (bullying at workplace) from the phenomena more clearly related to organizational anomalies on the whole (organizational stress) but also to evaluate their combined pathogenic effect; 2) to evaluate these phenomena without the on/off dichotomy but by means of a progressive grading of intensity; 3 ) to elaborate a simple and empirical tool to measure the effects of negative work environment on the bio-psycho-social individual level.

\section{METHODS}

The items of the nQ-WD were elaborated on the basis of two main sources: the clinical experiences of the teamwork of the Work Psychopathology Medical Centre (Department of Mental Health of Naples) and international scientific literature on this topic.

The first section of the questionnaire was composed of 32 items used to obtain information about socio-demographic data (sex, age, education level etc.), working variables (work sector, activity, work level and years of occupation, income bracket etc.): the items included between 18 and 31 explored the organizational characteristics (environment, safety, communication, leadership, workload, career opportunities etc.) to build the Organizational Scale (subscale OS). The answers concerning the items $18-26$ were evaluated on a 5-points Likaert scale $(-0.5,0,0.5,1$ and 2 points), while the answers to the items $27-32$ had a binary evaluation ( $0-1$ point $)$.

The second section explored the bullying at workplace phenomena (during the last $6-12$ months) and was made of 30 items. The sensitive items, used to build the Bullying at Workplace scale (subscale $\mathrm{H}$ ), of this section were from 38 to 59 and the item 61 . The answers explored the frequency of bullying behaviors (never, sometimes, frequently) and were evaluated on a 3-points Likaert scale $(0,1$ and 2 points), only the item 50 was evaluated on a $4-$ points Likaert scale $(-0.5,0,1$ and 2 points) and the item 61 had a binary evaluation ( $0-1$ point $)$.

Finally the third section has provided information about social and family adjustment, quality of life, psychologycal and physical well-being and has thus composed the BioPsycho-Social scale (subscale BPS). This section was made of 23 items, the sensitive items were eleven $(65,66$, $67,69,70,76,77,78,81,83,84)$ measured on a $3-$ points Likaert scale (items 65,70 and 76,78 ) or on a 4 points Likaert scale (items $66,67,69$ ) or on a 5 -points Likaert scale (items 81, 83, 84).

The random distribution of sensitive and non-sensitive items had the aim to reduce the mechanism of the leading questions [36].

The sum of scores of subscales OS, H and BPS built the overall score of the questionnaire (scale WD) measuring the global dimension of negative work psychosocial environment and its bio-psycho-social effect.

The nQ-WD was administered to 128 subjects (78 males and 50 females) in which was observed a clinical feature consistent with a work-related psychopathology. The study was carried out during a standardized sixmonths period of clinical observation to evaluate the weight of the work-induced pathogenesis degree according to our previous investigation [6].

The control sample was constituted of 118 workers, matched for sex, age and work level to the patients' sample. All controls were recruited among workers (without work-related health or psychiatric disturbances) who approached the Department of Preventive Medical Sciences of the University of Naples "Federico II". The control subjects who answered positively to the nQ-WD screening question "Have you been exposed to psychological kinds of harassment, constriction or injustice at workplace in the last year?" were excluded from the examination.

The internal consistency of the questionnaire was assessed using Cronbach's alpha coefficient [37]. Descriptive statistics was employed to analyze the collected data. Differences in central tendency between two groups were evaluated with Mann and Whitney U-test [38]. Demographic data were compared by means of two-sample t-test. The Spearman rank correlation analysis [38] was also carried-out. The validity of the questionnaire was studied 
applying ROC methodology [39].

\section{RESULTS}

Women were $38.8 \%$ of the group of patients suffering of a work-related psychopathology and $39.8 \%$ in the control group; the males were $61.2 \%$ vs $60.2 \%$. The two groups were similar concerning the age (patients $48.3 \pm 8.8$ vs controls $46.5 \pm 10.7)$, years of work $(16.73 \pm 11.0$ vs $19.4 \pm 11.3)$, years of education $(13.5 \pm 3.9$ vs $14.3 \pm$ $4.5)$. The odds ratio concerning the distribution of workers into the public or private work sector was also matched: 55/73 in the group of the patients and 54/74 in the group of the controls.

Cronbach's alpha was $0.80,0.82$ and 0.83 as concerns the items in the scales of Organizational Dysfunction, Bullying at Workplace and Bio-Psycho-Social area, respectively. Averaged values, standard deviations and some relevant percentilies of the above mentioned subscales are reported in the Tables 1-5. The results for the U-test are also shown.

Table 6 indicates the areas measured under ROC curves (AUC) and the parameters related to the subscale's discrimination performances.

The cut-off values were selected taking into account the nearest point of the left upper corner in the graph the ROC curves. In this way we obtain the best compromise between sensitivity and specificity.

Table 1. Organizational Dysfunction (scale OS): descriptive statistic \& Mann-Whitney U test results.

\begin{tabular}{cccc}
\hline & Patients & U test & Controls \\
\hline $\mathbf{m} \pm \mathbf{d s}$ & $13.6 \pm 3.5$ & $\mathrm{P}<0.0001$ & $6.16 \pm 3.9$ \\
\hline $\mathbf{1}^{\circ}$ decile & 8.2 & & 1.5 \\
$\mathbf{1}^{\circ}$ quartile & 11.5 & & 3 \\
Median & 14.5 & & 5.5 \\
$\mathbf{3}^{\circ}$ quartile & 16 & & 9 \\
$\mathbf{9}^{\circ}$ decile & 18 & 11.5 \\
\hline
\end{tabular}

Table 2. Bullying at Workplace (scale H): descriptive statistic \& Mann-Whitney U test results.

\begin{tabular}{cccc}
\hline & Patients & U test & Controls \\
\hline $\mathbf{m} \pm \mathbf{d s}$ & $22.2 \pm 7.4$ & $\mathrm{P}<0.0001$ & $5.54 \pm 5.5$ \\
\hline $\mathbf{1}^{\circ}$ decile & 12 & & 0 \\
$\mathbf{1}^{\circ}$ quartile & 18 & 1 \\
Median & 22 & 4 \\
$\mathbf{3}^{\circ}$ quartile & 27 & & 9.25 \\
$\mathbf{9}^{\circ}$ decile & 32 & & 14 \\
\hline
\end{tabular}

Table 3. Bio-Psycho-Social Area (scale BPS): descriptive statistic \& Mann-Whitney U test results.

\begin{tabular}{cccc}
\hline & Patients & U test & Controls \\
\hline m \pm ds & $12.2 \pm 8.3$ & $\mathrm{P}<0.0001$ & $3.70 \pm 4.1$ \\
\hline $\mathbf{1}^{\circ}$ decile & 0 & & -1 \\
$\mathbf{1}^{\circ}$ quartile & 2 & & 0 \\
Median & 15 & & 3 \\
$\mathbf{3}^{\circ}$ quartile & 19 & & 7 \\
$\mathbf{9}^{\circ}$ decile & 22 & 9.3 \\
\hline
\end{tabular}

Table 4. Overall Scores (scale WD): descriptive statistic \& MannWhitney $\mathrm{U}$ test results.

\begin{tabular}{cccc}
\hline & Patients & U test & Controls \\
\hline $\mathbf{m} \pm \mathbf{d s}$ & $48.0 \pm 14.0$ & $\mathrm{P}<0.0001$ & $15.4 \pm 11.6$ \\
\hline $\mathbf{1}^{\circ}$ decile & 28.8 & & 1.9 \\
$\mathbf{1}^{\circ}$ quartile & 37.75 & & 6 \\
Median & 48.5 & & 14 \\
$\mathbf{3}^{\circ}$ quartile & 58 & & 23.5 \\
$\mathbf{9}^{\circ}$ decile & 67 & & 33 \\
\hline
\end{tabular}

Table 5. OS Scale + H Scale: descriptive statistic \& U test results.

\begin{tabular}{cccc}
\hline & Patients & U test & Controls \\
\hline $\mathbf{~ m} \pm$ ds & $35.8 \pm 9.4$ & $\mathrm{P}<0.0001$ & $11.7 \pm 8.6$ \\
\hline $\mathbf{1}^{\circ}$ decile & 23.5 & & 1.7 \\
$\mathbf{1}^{\circ}$ quartile & 30 & & 4.9 \\
Median & 36.5 & & 10.5 \\
$\mathbf{3}^{\circ}$ quartile & 42 & & 17.5 \\
$\mathbf{9}^{\circ}$ decile & 47.8 & & 25.6 \\
\hline
\end{tabular}

Table 6. Summary of the parameters of ROC analysis.

\begin{tabular}{cccc}
\hline & Scale OS & Scale H & Overall Score \\
\hline AUC & 0.91 & 0.95 & 0.95 \\
\hline CUT-OFF & $\mathbf{1 0 . 5}$ & $\mathbf{1 3}$ & $\mathbf{3 4}$ \\
Sensitivity & $\approx 0.812$ & $\approx 0.879$ & $\approx 0.845$ \\
Specificity & $\approx 0.837$ & $\approx 0.837$ & $\approx 0.922$ \\
Positive predictive value & $\approx 0.852$ & $\approx 0.861$ & $\approx 0.926$ \\
Negative predictive value & $\approx 0.794$ & $\approx 0.857$ & $\approx 0.838$ \\
\hline
\end{tabular}

The Spearman correlation coefficient between OS and $\mathrm{H}$ subscales, calculated in the group of the subjects who underwent bullying at workplace, was $\approx 0.4(\mathrm{P}<0.001)$.

\section{DISCUSSION}

According to Bland and Altman [37] Cronbach's alpha values, lying between 0.70 and 0.80 , are regarded as satisfactory to compare groups, whereas in clinical settings, when the value of the scale for an individual is of interest, a minimum alpha of 0.90 is desirable. Our values, in the range of $0.80-0.83$, indicate, however, a good degree of internal consistency. The groups showed differences in central tendency, in fact controls had lower median values in all subscales (see Tables 1-6). ROC analysis indicates cut-off levels to separate controls and subjects suffering from work distress. In fact AUC values were all greater than 0.90 ; this result suggests that the proposed questionnaire has a good discriminative ability. The OS and $\mathrm{H}$ subscales were found correlated; the estimated value of Spearman coefficient is indicative that both score to determinate the overall cut-off level.

These results allow considering the nQ-WD as an effective tool to assess both organizational dysfunctions and bullying at workplace in their single dimensions as well as in their overall weight on the psychological wellbeing evaluated in term of the bio-psycho-social adjustment.

In agreement with these observations, therefore, the Naples-Questionnaire of Work Distress (nQ-WD), along 
with the standardized clinical diagnostic trials and the psycho-diagnostic tools, could aid the evaluation of the pathogenic effects of negative psychosocial work environment.

\section{REFERENCES}

[1] Godin, I., Kittel, F., Coppieters Y. and Siegrist, J. (2005) A prospective study of cumulative job stress in relation to mental health. BMC Public Health, 5, 67. doi:10.1186/1471-2458-5-67

[2] Stansfeld, S. and Candy, B. (2006) Psychosocial work environment and mental health-A meta-analytic review. Scandinavian Journal of Work, Environment \& Health, 32, 443-462. doi:10.5271/sjweh. 1050

[3] Wang J. (2005) Work stress as a risk factor for major depressive episode(s). Psychological Medicine, 35, 865871. doi:10.1017/S0033291704003241

[4] Sanderson, K. and Andrews, G. (2006) Common mental disorders in the workforce: Recent findings from descriptive and social epidemiology. Canadian Journal of Psychiatry, 51, 63-75.

[5] Girardi, P., Monaco, E., Prestigiacomo, C., Talamo, A., Ruberto, A. and Tatarelli, R. (2007) Personality and psychopathological profiles in individuals exposed to mobbing. Violence and Victims, 22, 172-188. doi:10.1891/088667007780477320

[6] Nolfe, G., Petrella, C., Blasi, F., Zontini, G. and Nolfe, G. (2008) Psychopathological dimension of the harassment at the workplace (mobbing). International Journal of Mental Health, 36, 70-88.

[7] McDaid, D. (2007) The economics of mental health in the workplace: What do we know and where do we go? Epidemiologia e Psychiatria Sociale, 16, 294-298.

[8] Johnston, K., Westerfield, W., Momin, S., Phillippi, R. and Naidoo, A. (2009) The direct and indirect costs of employee depression, anxiety, and emotional disorders-an employer case study. Journal of Occupational and Environmental Medicine, 51, 564-577. doi:10.1097/JOM.0b013e3181a1f5c8

[9] Einarsen, S., Hoel, H., Zapf, D. and Cooper, C.L. (2003) Bullying and emotional abuse in the workplace: International perspectives in research and practice. Taylor \& Francis, London.

[10] Roberts, R.K., Swanson, N.G. and Murphy, L.R. (2004) Discrimination and occupational mental health. Journal of Mental Health, 13, 129-142. doi:10.1080/09638230410001669264

[11] Fujishiro, K. and Heaney, C.A. (2009) Justice at work, job stress, and employee health. Health Education \& Behavior, 36, 487-504. doi:10.1177/1090198107306435

[12] Vanroelen, C., Levecque, K., Moors, G., Gadeyne, S. and Louckx, F. (2009) The structuring of occupational stressors in a Post-Fordist work environment. Moving beyond traditional accounts of demand, control and support. Social Science \& Medicine, 68, 1082-1090. doi:10.1016/j.socscimed.2009.01.012

[13] Kessler, R.C., Akiskal, H.S., Ames, M., Birnbaum, H., Greenberg, P., Hirschfeld, R., Jin, R., Merikangas, K.R. and Wang, P.S. (2006) Prevalence and effects of mood disorders on work performance in a nationally representative sample of US workers. American Journal of Psychiatry, 163, 1561-1568. doi:10.1176/appi.ajp.163.9.1561

[14] Woo, J.M. and Postolache, T.T. (2008) The impact of work environment on mood disorders and suicide: Evidence and implications. International Journal on Disability and Human Development, 7, 185-200. doi:10.1515/IJDHD.2008.7.2.185

[15] Niedhammer, I. and Chea, M. (2003) Psychosocial factors at work and self-reported health: Comparative results of cross sectional and prospective analyses of the French Gazel cohort. Occupational and Environmental Medicine 60, 509-515. doi:10.1136/oem.60.7.509

[16] Virtanen, M., Honkonen, T., Kivimäki, M., Ahola, K., Vahtera, J., Aromaa, A. and Lönnqvist, J. (2007) Work and stress, mental health and antidepressant medication finding from the Health 2000 Study. Journal of Affective Disorders, 98, 189-197. doi:10.1016/j.jad.2006.05.034

[17] Karasek, R.A. (1979) Job demands, job decision latitude, and mental strain: Implications for job redesign. Administrative Science Quarterly, 24, 285-308. doi: $10.2307 / 2392498$

[18] Siegrist, J. (1996) Adverse health effects of high-effort/ low-reward conditions. Journal of Occupational Health Psychology, 1, 27-41. doi:10.1037/1076-8998.1.1.27

[19] Tepper, B.J. (2001) Health consequences of organizational injustice: Tests of main and interactive effects. Organizational Behavior and Human Decision Processes, 86, 197-215.

[20] Kopp, M.S., Skrabski, A., Székely, A., Stauder, A. and Williams, R. (2007) Chronic stress and social changes: Socioeconomic determination of chronic stress. Annals of the New York Academy of Sciences, 1113, 325-338. doi:10.1196/annals.1391.006

[21] Lau, B. and Knardahl, S. (2008) Perceived job insecurity, job predictability, personality, and health. Journal of Occupational and Environmental Medicine, 50, 172-181. doi:10.1097/JOM.0b013e31815c89a1

[22] Andrea, H., Bültmann, U., van Amelsvoort, L.G. and Kant, Y. (2009) The incidence of anxiety and depression among emplyees-The role of psychosocial work characteristics. Depression and Anxiety, 26, 1040-1048. doi:10.1002/da.20516

[23] Landsbergis, P.A. (2003) The changing organization of work and the safety and health of working people: A commentary. Journal of Occupational and Environmental Medicine, 45, 61-72. doi:10.1097/00043764-200301000-00014

[24] International Labor Organisation Bureau for Workers' Activities. (2004) Labour Market Trends and Globalization's Impact on Them. International Labor Organisation, Geneva.

[25] Nolfe, G., Petrella, C., Zontini, G., Uttieri, S. and Nolfe, 
G. (2010) Association between bullying at work and mental disorders: Gender differences in the Italian people. Social Psychiatry and Psychiatric Epidemiology, 45, 1037 1041. doi:10.1007/s00127-009-0155-9

[26] Zapf, D. (1999) Organisational, work group related and personal causes of mobbing/bullying at work. International Journal of Manpower, 20, 57-69. doi:10.1108/01437729910268669

[27] Agervold, M. (2009) The significance of organizational factors for the incidence of bullying. Scandinavian Journal of Psychology, 50, 267-276. doi:10.1111/j.1467-9450.2009.00710.x

[28] Vartia, M. (1996) The source of bullying: Psychological work environment and organizational climate. European Journal of Work and Organizational Psychology, 5, 203214. doi:10.1080/13594329608414855

[29] Monaco, E., Bianco, G. Di, Simone Di Giuseppe, B. and Prestigiacomo, C. (2004) Patologie emergenti in Medicina del Lavoro: Il mobbing. Giornale Italiano di Medicina del Lavoro ed Ergonomia, 26, 28-32.

[30] Björkqvist, K., Österman, K. and Hjelt-Bäck, M. (1994) Aggression among university employees. Aggressive Behavior, 20, 173-184.

doi:10.1002/1098-2337(1994)20:3<173::AID-AB248020 $\underline{0304>3.0 . \mathrm{CO} ; 2-\mathrm{D}}$

[31] Einarsen, S. and Raknes B.I. (1997) Harassment in the workplace and the victimization of men. Violence and Victim, 12, 247-263.

[32] Zapf, D. and Einarsen S. (2003) Individual antecedents of bullying: Victims and perpetrators. In: Einarsen, S., Hoel, H., Zapf, D. and Cooper, C.L., Eds., Bullying and Emotional Abuse in the Workplace. International Perspectives in Research and Practice. Taylor \& Francis, London, 165-184.

[33] Leyman, H. (1990) Mobbing and psychological terror at workplaces. Violence and Victims, 5, 119-126.

[34] Einarsen, S. and Hoel, H. (2001) The Negative Acts Questionnaire: Development, validation and revision of a measure of bullying at work. 10th European Congress on Work and Organizational Psychology, 16-19 May 2001, Prague, Czech Republic.

[35] Einarsen, S., Hoel, H. and Notelaers, G. (2009) Measuring exposure to bullying and harassment at work: Validity, factor structure and psychometric properties of the Negative Acts Questionnaire-revised. Work \& Stress, 23, 24-44. doi:10.1080/02678370902815673

[36] Bailey, K.D. (1982) Methods of social research. Free Press, New York, 1982.

[37] Bland, J.M. and Altman, D.G. (1997) Cronbach's alpha. British Medical Journal, 314, 572. doi:10.1136/bmj.314.7080.572

[38] Pratt, J.W. and Gibbons, J.D. (1981) Concepts of non parametric theory. Springer series in statistics. SpringerVerlag, New York.

[39] Hanley, J.A. and Mc Neil, B.J. (1982) The meaning and the use of the area under a receiver operating characteristic (ROC) curve. Radiology, 143, 29-36. 